\title{
Strategic Thinking: The Role in Successful Management
}

\author{
Marcelo Amaral Dionisio \\ Coppead Graduate School of Business \\ Rua Pascoal Lemme, 355 - Cidade Universitária - RJ, Brazil \\ Tel: 55(21) 9-8878-3480Ｅ-mail: marcelo.dionisio@coppead.ufrj.br
}

Received: June 25, 2017

Accepted: August 7, 2017

Published: October1, 2017

doi:10.5296/jmr.v9i4.11448

URL: https://doi.org/10.5296/jmr.v9i4.11448

\begin{abstract}
Strategic thinking and strategic planning are concepts that are not clearly defined both in the literature and in the practice of business organizations and sometimes they are used interchangeably with each other or with strategic management. The purpose of this text is to differentiate and define both concepts and relate their role with the strategic decision making process of a firm. The text ends by approaching the issue of sustainability as a new challenge in the strategic process.
\end{abstract}

Keywords: Strategy, Strategic Thinking, Strategic Planning, Leadership 


\section{Introduction}

There is still a widespread agreement that strategic thinking is important for efficient management of firms, but it is often absent or at least lacking (Bonn, 2001; Liedtka, 1998). The gap in practice is followed by historical confusion of the concept among both scholars and practitioners, where the terms strategic thinking, strategic planning, and strategic management are used interchangeably (Mintzberg, 1994a). Goldman \& Casey (2010) state:

"In addition to the deficit in the literature regarding strategic thinking, there is a gap in practice. Top leaders' absence of strategic thinking has been identified as a major detractor of firm performance in studies across industries and countries (Bonn, 2001; Essery, 2002; Mason, 1986; Zabriskie \& Huellmantel, 1991). There is concern that this gap will continue: Bonn (2005) noted that strategic thinking was identified by a panel of experts as one of the 10 most critical areas for future management research. In addition, both leadership and strategy theorists have indicated that strategic thinking is needed at multiple organizational levels." (p. 120)

In this sense, Goldman et al (2015) argue that "Despite the consensus on the need for strategic thinking and the general advice that it should be nurtured by organizations, there is sparse literature on what organizations actually do to help leaders, managers, and others employed by the organization develop their ability to think strategically, how they do it, why they do it, and the degree to which their efforts are effective." (p. 155)

In the case of strategic decision making, Eisenhardt \& Zbaracki (1992) affirm that:

"Central among strategic process issues is strategic decision making. It is crucial because it involves those fundamental decisions which shape the course of a firm. During the past 30 years, many researchers have recognized the centrality of the topic by tackling issues in strategic and more generally, organizational decision making. (...) However, a quick examination suggests that the character of the field resembles a 'crazy quilt' of perspectives. A more thorough scrutiny reveals a field based on mature paradigms and incomplete assumptions." (p. 17)

In the case of strategic planning, Henry Mintzberg, maybe the more incisive author describing the way this concept has been misunderstood posits:

"When strategic planning arrived on the scene in the mid-1960s, corporate leaders embraced it as "the one best way" to devise and implement strategies that would enhance the competitiveness of each business unit. (...) Planning systems were expected to produce the best strategies as well as step-by-step instructions for carrying out those strategies so that the doers, the managers of businesses, could not get them wrong. As we now know, planning has not exactly worked out that way." (Mintzberg 1994a; p. 107)

Through a literature review this paper demonstrates within various different studies since 1985 that companies lack the correct application of corporate strategy in their practice by a general misconception of the different strategy concepts. It further aims to present new insights into strategy thinking and clarify the relationship and the meaning of these three 
different concepts of strategy - thinking, planning and decision making - contributing to encourage a culture of strategic thinking and also triggering further studies about the application of strategic thinking and its impact in business performance, especially in times that claims for organizational changes due to the need of sustainable development.

The paper starts by establishing the difference between strategic planning and strategic thinking and further develop each concept to finally align them with the strategic decision making process. The text finishes by exploring the current changes in organization's strategies due to sustainability demands and how the adoption of strategic thinking will be central for future growth and success of firms.

\section{Methodology}

This paper is inspired in three articles from Ingrid Bonn (2001, 2005, 2011) and complemented with the results from a search in the scientific resources EBSCO and Google Scholar with the subjects "strategic thinking", "strategic planning", "strategic decision making" and "strategic management", published since 1985 that occasioned a selection of 35 articles from main cited authors such as: Ellen Goldman (6), Henry Mintzberg (6), Jeanne Liedtka (4) Kathleen Eisenhardt (3), Michael Porter and Loizos Heracleous.

This research was substantiated by classic books such as Cyert \& March (1963) "A behavioral theory of the firm" and Ansoff (1965) "Corporate Strategy" and with seminal articles such as Mintzberg "Patterns in strategy formation" from 1978 and Prahalad \& Hamel "Strategic intent" from 1989.

\section{Literature Review}

\subsection{Why do companies need strategy?}

Mintzberg (1978) posits: "What are strategies and how are they formed in organizations? A large body of literature, under the title of strategy formulation in the private sector, and policymaking in the public sector, addresses the question of how organizations make and interrelate their significant (that is, strategic) decisions." (p. 934).

Liedtka (2000) states that the field of strategy, has been basically concerned with the search for sustainable competitive advantage and as the pace of change in the business environment accelerates, this focus translates into a strategy process concerned with equipping organizations with the capability to deal successfully with this changing environment.

Hamel \& Prahalad (1993) gives the following answer to the question "What is strategy?":

"For a great many managers in large Western companies, the answer centers on three elements: the concept of fit, or the relationship between the company and its competitive environment; the allocation of resources among competing investment opportunities; and a long-term perspective in which "patient money" figures prominently." (p. 77)

To better understand the need of strategy, Ansoff (1963) gives the alternative of "no strategy" and states: "The question of the usefulness of strategy as a management tool must, therefore, be examined. We will do this by first examining the alternative to strategy. This alternative is 
to have no rules beyond the simple decision to look under these conditions the firm for profitable prospects does not select formal objectives, performs no appraisals, formulate no search and evaluation rules." (p. 112)

So the literature goes on and on explaining what is strategy and why companies need them, and even though these definitions and ideas vary, there is one clear conclusion and that is that strategy is necessary to allow firms to reach their objectives, results and thus grow and survive.

\subsection{Strategic thinking versus strategic planning}

Ansoff (1965) stated that "As every experienced executive knows, a major part of a manager's time is occupied in a daily process of making numerous and diverse decisions." (p.1), and since then, the search for the right strategy to improve decision making and enhance competitive advantage has troubled a lot of managers and corporate leaders (Mintzberg, 1994c) and still today this seems to be the case, as Reeves et al (2015) affirm "In a business environment that is changing faster and becoming more uncertain and complex almost by the day, it's never been more important to choose the right approach to strategy." (p. 2).

Mintzberg (1994c) has called the attention to the fact that companies were mixing concepts, between strategic planning, thinking and programming, and between visions and plans which would only lead them to the wrong direction they should pursue. He is adamant affirming that "Strategic planning is not strategic thinking" (p. 107).

This idea is shared by Bonn (2001) who states: "There is no agreement in the literature on what strategic thinking is. A number of authors have used the term interchangeably with other concepts such as strategic planning or strategic managing." (p. 63).

Heracleous (1998) reinforces this idea by positing that "An exploration of the literature reveals that there is no agreement on what strategic thinking is, what strategic planning is, or what their relationship should be.” (p. 482).

These misconceptions were confirmed in studies by Goldman (2012)in the period between 1985-2010 which identified that the absence of strategic thinking at top leaders was a major cause of organizational performance and when strategic thinking was present, better corporate decisions would have been made and greater value provided to constituents.

Three reasons for the strategic thinking gap have been suggested in the literatue: a lack of understanding of the concept overall; constant practitioner and theoretician confusion of the term "strategic thinking" with "strategic planning" as well as other strategic management terms and tools such as a SWOT (strengths, weaknesses, opportunities, and threats) analysis and limited development of strategic thinking among organizational leaders (Goldman and Casey, 2010; Bonn 2001; Goldman 2009, 2012).

This becomes even more critical in today's scenario where "Managers and other business leaders face a dilemma: with increasingly diverse environments to manage and rising stakes 
to get it right, how do they identify the most effective approach to business strategy (...)?" (Reeves et al 2015, p. 4)

Heracleous (1998) differentiates both concepts as follows: "Strategic planning is often used to refer to a programmatic, analytical thought process and strategic thinking to refer to a creative, divergent thought process." (p. 481).

This notion is reinforced by Mintzberg (1994c) who says that "Planning has always been about analysis -about breaking down a goal or set of intentions into steps, formalizing those steps so that they can be implemented almost automatically and articulating the anticipated consequences or results of each step. (...) [and] Strategic thinking, in contrast, is about synthesis. It involves intuition and creativity. The outcome of strategic thinking is an integrated perspective of the enterprise.” (p. 108)

Liedtka (2000) argues that Strategic Planning follows strategic thinking, and then selects objectives, product/market choices and other functions of coordination and control. As Ansoff (1965) states, strategy can be used within the planning process of the business firm.

It can be concluded that a strategic plan always takes a long-term view, generally projecting future financial returns, estimating future risks that affect shareholder value, and deciding what needs to be achieved (Sokol, 1992; Richardson, 2010).

While this practical and analytical side of strategic planning is key for the decision making process of companies, the more subjective attribute of strategic thinking is fundamental for their success, so let us further explore this concept.

\subsection{The role of strategic thinking}

The literature defines strategic thinking broadly as an essential component of strategy development, a mental, reflective and issue oriented process that has the purpose to develop new strategies and that may happen before, during or after strategic planning. (Goldman, 2012; Heracleous, 1998; Liedtka, 1998)

Despite the already known concepts of strategic thinking, Bonn (2005) calls the attention for the fact that "there is a need for more research that can help us to better understand strategic thinking. Such understanding would provide an important missing link in strategic management research and enable us to obtain a more realistic picture of strategic decision-makers and decision-making. In addition, it would help practicing managers to develop strategies for improving strategic thinking in their organizations." (p. 337). Her own definition of strategic thinking is:

“(...) a way of solving strategic problems that combines a rational and convergent approach with creative and divergent thought processes. Such process orientation focuses this investigation on how senior managers in an organizational setting attempt to understand and take strategic action in an environment that is highly complex, ambiguous and competitive. It represents an important antecedent to strategic decision-making and may provide a key to better understand organizational change phenomena and ultimately, organizational performance and survival." (Bonn 2005; p. 337) 
The definition of Liedtka (2000) is "First, strategic thinking is synthetic. It seeks internal alignment and understands interdependencies. It is systemic in its focus. It requires the ability to understand and integrate across levels and elements, both horizontal and vertical, and to align strategies across those levels. Strategic thinking is built on the foundation of a systems perspective. A strategic thinker has a mental model of the complete end-to-end system of value creation, and understands the interdependencies within it." (p. 21).

Another way to define strategic thinking is that it is a conceptual, systems oriented, directional and opportunistic process that leads the discovery of new and imaginative strategies that are implemented as it is made. (Casey \& Goldman, 2010; Mintzberg 1978; Liedtka, 1998; Heracleous, 1998)

This imaginative, mental and creative characteristics identified with the strategic thinking definition can be related to the concept of strategic intent, defined by Hamel \& Prahalad (1989) as an obsession with winning, an envision of desired leadership position, a concept that encompasses an active management process, motivating people and leaving room for individual and group contribution, sustaining enthusiasm and using intent to consistently guide resource allocation allowing companies to go beyond their resources and capabilities.

They state that: "Strategic intent provides consistency to short-term action, while leaving room for reinterpretation as new opportunities emerge.” (p. 151).

Nuntamanop, Kauranen and Igel (2013) state that “(..) a common definition of strategic thinking in terms of its characteristics is not found" (p. 245) and thus complement the presented definitions of strategic thinking as: the development of thinking concepts, skills, styles and techniques; as visionary, intuitive and consistent; and comments that strategic thinking is key to corporate survival lies and that strategic thinking is essential for strategic planning.

The importance of the role of strategic thinking can be explained twofold: by the company's need to find and adopt the right strategy and, based on the literature, by the lack of efficient strategic thinking in organizations.

Porter (1991) affirms that "The reason why firms succeed or fail is perhaps the central question in strategy." (p. 95) while Pretorius (2008) says that "The cause of decline and failure is frequently classed as either strategic or operational in nature (...) strategic causes have to do with weak or wrong positioning in the market, technological changes that govern demand determinants and loss of competitive advantage by the venture (...) strategic causes generally require more speedy action.” (p. 21).

Liedtka (2006) calls a "duck" the creation of symbols and says that "Much the same thing is happening in many business organizations today. In an effort to appear "strategic," corporations are creating a lot of ducks - strategies that function as symbols, not roadmaps. Strategies that appear, at a distance, to be appealing and engaging - but up close, just aren't of much use to anyone - especially the people in the organization who need them most." (p. $32)$. 
Nuntamanop et al (2013) posit that "Despite a wide consensus on the importance of strategic thinking to business performance, an extensive literature review has found few studies that define what strategic thinking is or empirically verify how strategies and strategic actions business leaders in practice take relate to strategic thinking." (p. 243).

Goldman (2012) finds out that "At the same time the gap at the top [management] is recognized, so is the need to develop the strategic thinking ability of those at deeper levels in organizations. The nature of today's work environments requires individuals to interpret complex information and develop strategies that improve organizational processes and routines." (p. 26).

In a study with 35 out of 100 largest manufacturing companies in Australia in 1993, Bonn (2001) found out through interviews with senior executives responsible for strategic planning, strategic management or corporate development that "The main problem identified by the majority of senior executives was strategic thinking." (p. 63), she concludes by saying that "My analysis has shown that individual members, particularly senior managers, should have a holistic understanding of the organization and its environment, they should be creative, and they should have a vision of the future of the organizations." (p. 69). All attributes of strategic thinking.

Goldman, Scott \& Follman (2015) conclude that "There is widespread agreement that strategic thinking is important for the direction and sustainability of organizations, but is often absent or at least significantly lacking." (p. 155).

\subsection{Planners and managers and the strategic decision making process}

Once the concepts between strategic thinking and strategic planning are differentiated, it is important to clearly define the role of planners, to improve the decision making process and the search for competitive advantage, as Porter (1996) states "Competitive strategy is about being different. It means deliberately choosing a different set of activities to deliver a unique mix of value." (p. 64).

Mintzberg (1994a) defines planning as a "formalized procedure to produce articulated result, in the form of an integrated system of decisions. In other words, planning is about formalization, which means the decomposition of a process into clearly articulated steps. Planning is thus associated with 'rational' analysis" (p. 13), is a process that should occur after strategic thinking (Mintzberg 1994c, Bonn 2001) in a way that encourages strategic thinking and not to discourage it (Mintzberg 1994b).

Mintzberg (1994b) differentiates the roles of planners and managers, where the former have time, certain techniques and most importantly an inclination to do analysis. He states that they lack the manager's authority to make commitments, and more importantly, the managers' access to soft information critical to strategy making, although they can encourage strategic thinking. According to him, managers tend to favor action over reflection and the oral over the written. 
In this sense, Hamel \& Prahalad (1993) state "Every day, employees come in contact with new customers, learn more about competitors, confront and solve technical problems, and discover better ways of doing things. But some companies are better than others at extracting knowledge from those experiences." (p. 80).

Mintzberg (1994a, 1994b) claims that, based on literature research and his own experiences, in most cases what is called strategic planning is in reality strategic programming and that "given viable, stable strategies, the role of planning- the one role of planning-becomes to program them, that is, to implement rather than formulate them." (Mintzberg 1994b; p. 23).

In any case, it is important for companies to allow the correct integration between planners and managers so strategy do not become rigid and bureaucratic, and leads to a situation identified by Sokol (1992) that states that "When talking to presidents of small to medium-size companies, I frequently encounter the following complaint. They have a 100-page strategic plan, developed by outside consultants. It was never implemented.” (p. 11)

Consequential to the correct alignment between planners and managers is effective strategic decision-making, a topic of great interest in the field of strategic management (Eisenhardt and Zbaracki 1992) which previous studies have provided important insights into its processes (Eisenhardt 1989). Bonn (2005) claims that a better understanding of strategic thinking "would provide an important missing link in strategic management research and enable us to obtain a more realistic picture of strategic decision-makers and decision-making. In addition, it would help practicing managers to develop strategies for improving strategic thinking in their organizations." (p. 337)

Cyert \& March (1963) states that "If we wish to develop a theory that predicts and explains business decision-making behavior, we face a problem that can be paraphrased in terms of the following: 1) People (i.e., individuals) have goals; collectivities of people do not. 2) To define a theory of organizational decision making, we seem to need something analogous - at the organizational level - to individual goals at the individual level." (p. 30)

Bonn (2011) states that: "The strategic decision-making process is concerned with the way decisions are reached in an organizational setting and includes the activities that lead up to and support the choice of strategy." (p. 7).

In this sense, studies propose that strategic thinking should be addressed at both individual and group levels in order to improve quality of strategic decisions (Bonn 2001, 2005; Amason \& Schweiger 1994). They reinforce the idea that to successfully implement decisions companies need the participation of team members, in a context where employees can contribute to the overall vision of the organization and allow creativity and innovation. Bonn (2001) states that "The challenge for senior managers is to design and establish a working environment where everyone is encouraged to explore new ideas and to come up with improvements and innovations." (p. 68).

By involving both the individual and the group level of the company's employees and addressing the elements of strategic thinking (systems thinking, creativity, vision, etc.) managers are able to constantly scan the internal and the external environments and help them 
make decisions. In their studies, Steptoe-Warren, Howat \& Hume (2011) argues that "It was asserted that strategies formulated with knowledge from middle management and other relevant individuals within an organization, rather than just the strategic thinker are likely to be superior as consideration is given to both information regarding what actions are required as well as whether the actions to betaken are operationally possible in terms of resources (staff and materials etc.)" (p. 240).

The concept developed by Eisenhardt, Kahwajy \&Bourgeois III (1997) reinforces this idea by affirming that "the ability of senior executives to work together as a cohesive and effective team is critical to the success of the firm. Together, members of the top management team not only shape the vision of the corporation, but also articulate and execute that vision through an on-going series of group interactions and decisions. Their ability to engage in effective teamwork can determine the success of the firm." (p. 42)

Steptoe-Warren et al (2011) posits that "It appears that strategic thinkers and decision makers need to be able to adapt and change to meet the demands of the marketplace (values associated with vision), whilst also motivating and encouraging employees to commit to the changes and work towards the new vision (operating values).” (p. 245)

This idea is also shared by Liedtka (2000) that affirms "Scholars studying the topic of the broader inclusion of managers in strategy-making processes have noted a number of significant advantages to such inclusion.” (p. 198)

The implication of the lack of alignment between strategy and all the levels of an organization is better described by Bower \& Gilbert (2007) in their article where they analyze the roles of midlevel managers in different companies and find out that sometimes they make decisions by themselves regardless the orientation of headquarters and thus the strategy of the company. They state:

"The fact hat at any company responsibility is divided up among various individuals and units has vital consequences for how strategy gets made." (p. 75). And follow: "Crafting strategy is an iterative, real-time process; commitments must be made, then either revised or stepped up as new realities emerge. (...) Because knowledge and power span organizational levels, managers at each level are likely to have an impact on strategy. External forces can also have a strong effect on how resources are allocated, and, in turn, how strategy evolves. The most powerful of these forces are the company's best customers and the capital markets. (Bower \& Gilbert 2007, p. 76)

As Steptoe-Warren et al (2011) conclude "The aim of strategic thinking and decision making is to ensure survival of the organization in a competitive marketplace. For this to occur there is a need for effective strategic thinking and decision making that steers the organization in the most appropriate direction." (p. 246)

\subsection{Sustainability: the missing link in strategy}

In the last 10 years, sustainability has become present in every company's strategy. Bonn (2011) states that: 
"A survey by KPMG in 2008 found that 47.7 per cent of companies considered sustainability and corporate responsibility an important driver of innovation (KPMG International, 2008). However, for the majority of companies, understanding how to make their businesses more sustainable was a challenge. The areas that posed the greatest challenge for approximately 80 per cent of companies were identifying and prioritizing issues, developing strategies and policies and measuring performance. This finding is in line with anecdotal evidence from our consulting work. The Director of Sustainability of a large manufacturing company in New South Wales, Australia, for example, stated: "for us, sustainability is important, both at the strategic and the operational levels. That is why we created the position Director of Sustainability about six months ago. However, for me, as Director of Sustainability, the challenge is to identify the areas that need a greater sustainability focus, to develop appropriate strategies and to oversee their implementation. [. . .] It is a very complex process." (p. 5)

This idea is shared by Stead and Stead (2013) that argues that sustainability has become central in society and it has also become a central concern in the business environment leading to a profound shift in the strategic context. They found out that:

"In the 2011 survey, researchers found that firms fully embracing sustainability as a key strategic issue were able to successfully implement profitable preemptive strategies in new socially and ecologically positioned market space, and they also found that firms that were only casually adopting sustainability as a strategic initiative were unable to effectively compete in this new market space. In the 2012 survey, $90 \%$ of the responding executives said that implementing sustainability strategies is now or will soon be a competitive necessity for their organizations, and $70 \%$ said that they have put sustainability on their strategic agendas within the past 6 years. In the 2013 survey, $50 \%$ of the responding executives said that they had changed their basic business models to incorporate sustainability because of the strategic opportunities that it provides them, a full $20 \%$ increase over the previous year's survey." (p. 163)

Bonn (2011) argues that: "for organizations to achieve sustainability, managers must address the different aspects of sustainability during the strategic decision-making process and incorporate them into their corporate, business and functional level strategies." (p. 5).

Stead and Stead (2013) identifies eight different sustainable strategies that may be applied to develop (6) and underdeveloped (2) markets: eco-efficiency, socio-efficiency, product stewardship, climate change, emerging business, sustainable marketing, co-evolution and BOP (base of the pyramid) strategies.

This new layer of difficulty in the strategy process is directly related to the issue of strategic thinking, as companies in order to succeed this new challenge must adopt a whole new vision in its organizational culture, at all levels, as Bonn (2011) states: "We argue that if organizations are to become more sustainable, then managers need to ensure that sustainability is integrated into the strategy process from the very beginning and is addressed on an ongoing basis." (p. 6). 
Bonn (2011) concludes that: “(...) we have identified problems managers experience when trying to make their organizations more sustainable. Some of these problems are due to managers addressing sustainability as an operational rather than as a strategic issue." (p. 13).

\section{Discussion and Conclusion}

This paper offers arguments to clearly differentiate the concepts of strategic planning and strategic thinking as developed in the last thirty years of research and identifies that there is still confusion between these concepts that have somehow influenced practitioners and academics during this period.

From a practitioner's perspective the literature suggests that there is still a lack of strategic thinking in companies which leads to bad strategies thus bad decisions, in a world that is getting more competitive, object of faster changes and with much more complex demands that can impact in the survival of these firms.

In agreement with the ideas of Liedka (2000), this paper defends the idea that strategic planning should follow strategic thinking and managers are key to implement strategies in order to design and establish a working environment where everyone is encouraged to explore new ideas and to come up with improvements and innovations, through a constant assessment of both external and internal environments, with more chances for improved results (Bonn 2001).

Based on the literature discussed in this paper, it can be concluded that the right alignment of these different concepts of strategy with focus on the development of strategic thinking would lead to better decisions that would improve results, especially when developed within all levels of the organization, both individual and with the group.

It is agreed that strategic thinking is a more creative, visionary and reflective process that provides a broader and better knowledge of the company and its business and allows a general improvement of management especially for the long term and thus avoid what has been pointed out by Mintzberg (1994a) as : “(...) the so-called five year plan [that] is nothing more than a mechanical extrapolation of current data, with no reflection of management decisions and judgment; such an exercise is totally worthless." (p. 58).

The relevance of this article becomes more evident in the moment that Reeves et al (2015) presents the large number of different strategies proposed in the last years at the same time that they propose a new strategy to improve business, when the mere understanding of classic, discussed concepts should be enough to allow managers to take the right path in the development of effective business strategies.

The sustainability issues offer an actual and relevant perspective showing that the business world is under demand for impactful changes with pressures from different stakeholders to change its business models and improve its products and procedures. These demands claiming for sustainable development is in the agenda of most large companies which only reinforces the need for an increased commitment of teams, a faster ability to react and new, 
integrated strategies that allows companies to correctly address these needs, which will be only possible through the development of strategic thinking in their day-to-day business.

No empirical data is presented, though many of the articles used to support the concepts are backed by statistics and case studies, nevertheless more extant and empirical research, that can identify and evaluate the strategic thinking ability of managers is suggested along with identification of criteria that can predict long term strategic thinking ability.

\section{References}

Amason, A. C., \& Schweiger, D. M. (1994). Resolving The Paradox of Conflict, Strategic Decision Making, and Organizational Performance. International Journal of Conflict Management. https://doi.org/10.1108/eb022745

Ansoff, H. I. (1965). Corporate Strategy. An analytic approach to Business Policy for Grwoth and Expansion. McGraw \& Hill, New York.

Bonn, I. (2005). Improving strategic thinking: A multilevel approach. Leadership \& Organization Development Journal, 26(5), 336-354. https://doi.org/10.1108/01437730510607844

Bonn, I. (2001). Developing strategic thinking as a core competency. Management Decision. https://doi.org/10.1108/EUM0000000005408

Bonn, I., \& Fisher, J. (2011). Sustainability: the missing ingredient in strategy. Journal of Business Strategy. https://doi.org/10.1108/02756661111100274

Bower, J. L., \& Gilbert, C. G. (2007). Create or Destroy Your Company's Strategy. Harvard Business Review, (February 2007).

Casey, A. J., \& Goldman, E. F. (2010). Enhancing the ability to think strategically: A learning model. Management Learning. https://doi.org/10.1177/1350507609355497

Cyert, R. M., \& March, J. G. (1963). A Behavioral Theory of the Firm. Prentice Hall.

Eisenhardt, K. M., \& Zbaracki, M. J. (1992). Strategic decision making. Strategic Management Journal, 13, 17-37. https://doi.org/10.1002/smj.4250130904

Eisenhardt, K. M. (1989). MAKING FAST STRATEGIC DECISIONS IN HIGH-VELOCITY ENVIRONMENTS. Academy of Management Journal, 543-576. https://doi.org/10.2307/256434

Eisenhardt, K. M., Kahwajy, J. L., \& Bourgeois III, L. J. (1997). Conflict and strategic choice: How Top Management Teams disagree. California Management Review, 39(2), https://doi.org/10.2307/41165886

Goldman, E. (2009). Experiences That Develop the Ability to Think Strategically. Journal of Healthcare Management, 403-418.

Goldman, E. F. (2006). Strategic Thinking at the Top. AoM, 1-7. 
Goldman, E. F. (2012). Leadership practices that encourage strategic thinking. Journal of Strategy and Management. https://doi.org/10.1108/17554251211200437

Goldman, E. F., \& Casey, A. (2010). Building a Culture That Encourages Strategic Thinking. Journal of Leadershiop \& Organizational Studies. https://doi.org/10.1177/1548051810369677

Goldman, E. F., Scott, A. R., \& Follman, J. M. (2015). Organizational practices to develop strategic thinking. Journal of Strategy and Management, 8(2), 155. https://doi.org/10.1108/JSMA-01-2015-0003

Hamel, G., \& Prahalad, C. K. (1989). Strategic Intent. Harvard Business Review.

Hamel, G., \& Prahalad, C. (1993). Strategy as stretch and leverage. Harvard Business Review.

Heracleous, L. (1998). Strategic thinking or strategic planning? Long Range Planning, 31(3), 481-487. https://doi.org/10.1016/S0024-6301(98)80015-0

Liedtka, J. (1998). Strategic Thinking : Can it be Taught? Long Range Planning, 6301(97). https://doi.org/10.1016/S0024-6301(97)00098-8

Liedtka, J. (2006). Is your strategy a duck? Journal of Business Strategy.

Liedtka, J. (2000). In Defense of Strategy as Design. California Management Review, (3). https://doi.org/10.2307/41166040

Liedtka, J. (2000). Strategic Planning as a Contributor to Strategic Change: A Generative Model. European Management Journal, 18(2), 195-206. https://doi.org/10.1016/S0263-2373(99)00091-2

Mintzberg, H. (1994a). The Fall and Rise of Strategic Planning. Harvard Business Review, 107-114.

Mintzberg, H. (1994b). Rethinking strategic planning part I: Pitfalls and fallacies. Long Range Planning, 27(3), 12-21. https://doi.org/10.1016/0024-6301(94)90185-6

Mintzberg, H. (1994c). Rethinking strategic planning part II: New roles for planners. Long Range Planning, 27(3), 22-30. https://doi.org/10.1016/0024-6301(94)90186-4

Mintzberg, H., \& Waters, J. (1985). Of Strategies , Deliberate and Emergent. Strategic Management Journal, 6(March 1983), 257-272. https://doi.org/10.1002/smj.4250060306

Mintzberg, H., \&Westley, F. (1992). Cycles of organizational change. Strategic Management Journal, 13, 39. https://doi.org/10.1002/smj.4250130905

Mintzbergt, H. (1978). PATTERNS IN STRATEGY FORMATION. Management Science, 24(9), 934-949. https://doi.org/10.1287/mnsc.24.9.934 


\section{Macrothink}

Journal of Management Research

ISSN 1941-899X 2017, Vol. 9, No. 4

Nuntamanop, P., Kauranen, I., \& Igel, B. (2013). A new model of strategic thinking competency. Journal of Strategy and Management. https://doi.org/10.1108/JSMA-10-2012-0052

Porter, M. E. (1991). Towards a dynamic theory of strategy. Strategic Management Journal, 12. https://doi.org/10.1002/smj.4250121008

Porter, M. E. (1996). What is strategy? Harvard Business Review, (December).

Pretorius, M. (2008). When Porter's generic strategies are not enough: complementary strategies for turnaround situations. Journal of Business Strategy, 29(6), 19-28. https://doi.org/10.1108/02756660810917200

Reeves, M., Haanaes, K., \& Sinha, J. (2015). Navigating the Dozens of Different Strategy Options. Harvard Business Review, 16.

Richardson, B. (2010). Comprehensive Approach to Strategic Management. Management Decision.

Sokol, R. (1992). Simplifying Strategic Planning. Management Decision. https://doi.org/10.1108/00251749210017281

Stead, J. G., \& Stead, W. E. (2013). The Coevolution of Sustainable Strategic Management in the Global Marketplace. Organization \& Environment, 26(2), 162-183. https://doi.org/10.1177/1086026613489138

Steptoe-Warren, G., Howat, D., \& Hume, I. (2011). Strategic thinking and decision making: literature review. Journal of Strategy and Management, 4(3), 238-250. https://doi.org/10.1108/17554251111152261

\section{Copyright Disclaimer}

Copyright for this article is retained by the author(s), with first publication rights granted to the journal.

This is an open-access article distributed under the terms and conditions of the Creative Commons Attribution license (http://creativecommons.org/licenses/by/3.0/). 